\title{
Vulvar schwannoma: a case report
}

\author{
Barkha Bafna $^{1}$, Amit Bafna ${ }^{1}$, Ashalata Bafna ${ }^{2}$
}

\author{
${ }^{1}$ Consultant, Bafna Hospital, Dhule, Maharashtra, India \\ ${ }^{2}$ Department of Obstetrics and Gynecology, ACPM Medical, College, Dhule, Maharashtra, India
}

Received: 18 July 2016

Accepted: 09 August 2016

\author{
*Correspondence: \\ Dr. Barkha Bafna, \\ E-mail: barkhajainbafna@yahoo.com
}

Copyright: (c) the author(s), publisher and licensee Medip Academy. This is an open-access article distributed under the terms of the Creative Commons Attribution Non-Commercial License, which permits unrestricted non-commercial use, distribution, and reproduction in any medium, provided the original work is properly cited.

\begin{abstract}
Schwannoma is a benign, slow growing nerve sheath neoplasm that is rarely found in female genital system. Only a few cases of vulvar schwannomas have been reported. We report a case of vulvar Schwannoma arising in labium minus in a patient without neurofibromatosis. A 26 year old woman had two $1 \mathrm{~cm} \mathrm{x} 1 \mathrm{~cm}$ and $1.5 \mathrm{~cm} \times 2 \mathrm{~cm}$ sized oval nodules at the right labium minus. Complete excision was done and the histological report confirmed to be vulvar Schwannoma. Although it has a very low incidence, Schwannoma should be considered as a differential diagnosis of a vulvar mass.
\end{abstract}

Keywords: Schwannoma, Vulvar mass

\section{INTRODUCTION}

Schwannoma is also named as neurinoma, neurilemoma and schwann cell tumor. It is a benign tumor that arises from the schwann cells of peripheral, cranial or autonomic nerves. The most common locations are the head, neck, upper and lower extremities, posterior mediastinum and retroperitoneum. ${ }^{1}$ It seldom affects the female genitalia. To the best of our knowledge, epithelial tumors are the most common tumor in the vulvar region, and mesenchymal tumors comprise less than $10 \%$ of them. Schwannoma involving vulva is the least common. We report a case of vulvar schwannoma arising in labium minus in a patient without neurofibromatosis.

\section{CASE REPORT}

A 25 year old Indian women (para 1), presented with non-tender small palpable nodules at her right labium minus. The patient reported that she noticed a small nodule at the right labia minus five months back, now grown in size slightly and an additional similar swelling adjacent to it. The approximate sizes were 10x20x8 mm and $6 \times 6 \times 4 \mathrm{~mm}$ respectively. Her previous menstrual history was regular. On general examination, she was found to be of average build and there were no clinical signs indicative of neurofibromatosis 1 and 2 . On gynecologic examination, there was no abnormality except the palpable nodules. Surgical excision with clear margins was performed. The resected specimens were well circumscribed globular masses greyish white in colour.

On microscopic examination, a fibrous capsule was identified around the tumor. The tumor sections revealed a spindle cell neoplasm composed of cells exhibiting nuclear pallisading against an eosinophilic background, forming verocay bodies (Antoni A pattern). Few foci also showed loosely arranged cells with a more rounded morphology (Antoni B pattern). The individual tumor nuclei were bland, oval and with pointed ends (Figure 1). No necrosis was identified in any of the sections.

Immunohistochemically, the spindle cells were strongly positive for S-100 protien (Figure 2) and they were negative for SMA (smooth muscle actin). Hence the diagnosis of the benign schwannoma was made. The Ki67 index was low ruling out any possibility of a low grade sarcoma. 


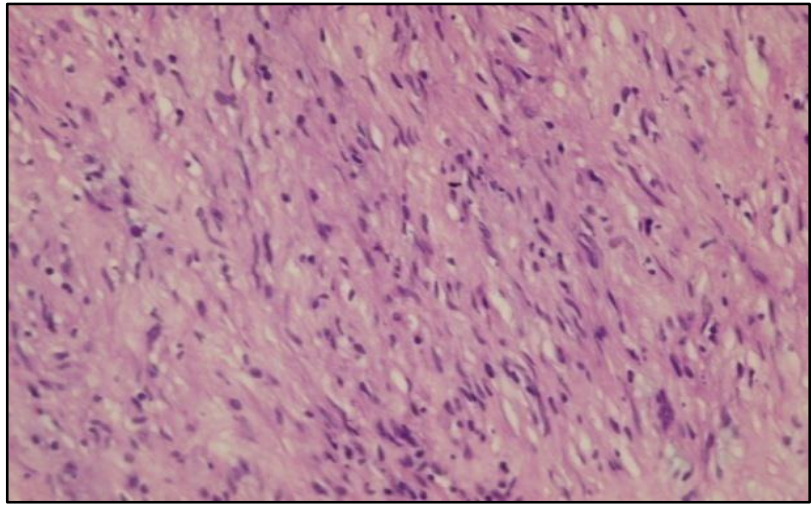

Figure 1: Histology: Antoni A and Antoni B areas.

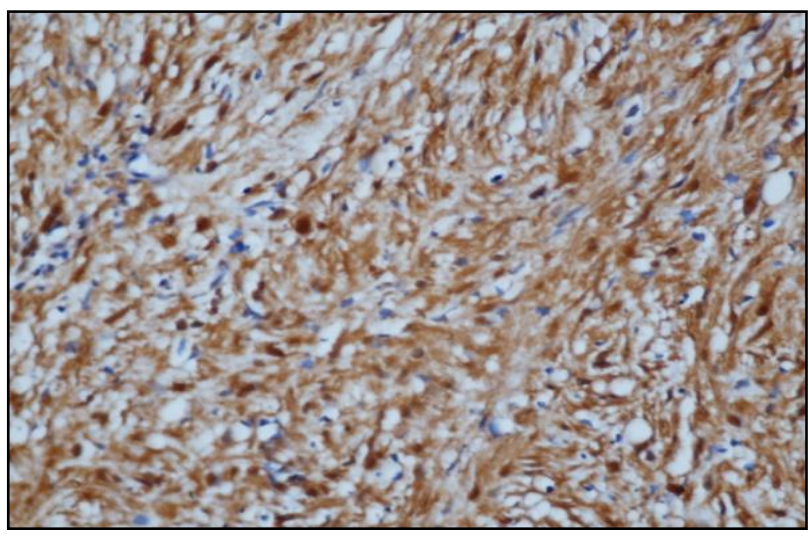

Figure 2: Spindle cells positive for $\mathrm{S}$ - $\mathbf{1 0 0}$ protein.

\section{DISCUSSION}

Schwannoma is a benign nerve sheath tumor composed of Schwann cells arising from the myelin sheath of peripheral nerves. Schwannoma are usually benign and less than $1 \%$ becomes malignant degenerating into a form of cancer known as neurofibrosarcoma. Shwannoma can arise from neurofibromatosis or it can occur sporadically. Of all neurogenic tumors, about half are found in the head and neck region. It has been described infrequently in female genital tract. ${ }^{2}$ Schwanomma rarely arises from female genital organs like the ovary, round ligament, cervix, clitoris and vulva.

The origin of schwannoma is most commonly associated with nerve trunk and clinical symptoms depend on the nerve of origin. Vulvar schwannoma is a slow growing well encapsulated benign tumor hence it presents with non-specific symptoms that are clinically indistinguishable from other cutaneous lesions of vulva like lipoma, fibroma and vulval cyst. Small masses are asymptomatic and discovered by chance. ${ }^{3}$ Treatment modality is surgical. Wide local excision is done. Tumors of the vulva are uncommon and may show relatively nonspecific symptoms. The pre-operative diagnosis of the vulvar neoplasm is difficult. Therefore, a biopsy is often needed to exclude a malignant neoplasm and to indicate proper treatment.

The characteristic histologic appearance can make the accurate diagnosis. Histologically, conventional variant is the most common of the vulvar schwannoma also plexiform and ancient variant of the vulvar schwannoma have been reported. ${ }^{3,4}$ Immunohistochemically malignant schwannoma are thought to be composed of dedifferentiated Schwann cells that had somewhat lost their capacity to synthesize S-100 protein. In our case most of the Schwann cells were strongly positive for S-100 protein. This supported the diagnosis of benign nature of the tumor.

Patient consent was obtained and patient identity was not disclosed.

\section{CONCLUSION}

Pre-operative gynecologic and radiologic examinations are so important for characterization and the differentiation of the benign and malignant vulvar mass and guiding the surgical treatment. A slow growing tumor with absence of lymph nodes goes in favour of benign nature of the mass. Surgical excision with clear margins, patient follow -up with histological confirmation should be the dictum in such cases. Although rare, schwannoma should be considered in the differential diagnosis of vulvar masses.

\section{Funding: No funding sources \\ Conflict of interest: None declared \\ Ethical approval: Not required}

\section{REFERENCES}

1. Weiss SW, Goldblum JR. Benign tumors of peripheral nerves. In: Weiss SW, Goldblum JR, editors. Enzinger and Weiss's soft tissue tumors. 5th ed. Philadelphia (PA):Mosby. 2008. 825-901.

2. Obeidat BR, Amarin ZO, Jallad MF. Vaginal schwannoma: A case report. J Reprod Med. 2007;52(4):341-2.

3. Kim NR, Cho HY, Lee SH. Vulvar Neurilemmoma at the labia minus. Korean J Obstet Gynecol. 2011;5:326-9.

4. Bozkurt M, Kara D. Giant vulvar Sxhwannoma: a case report. Acta Media Iranica. 2013;51:427-9.

Cite this article as: Bafna B, Bafna A, Bafna A. Vulvar schwannoma: a case report. Int J Reprod Contracept Obstet Gynecol 2016;5:3249-50. 